\title{
Performance Analysis and Simulation of a Five Level Inverter with Coupled Inductors
}

\author{
S. Nandini \\ AP, EEE Department \\ Maharaja Institute of Technology \\ Coimbatore-641407, India.
}

\author{
Reeba Sara Zachariah \\ PG Scholar, EEE Department \\ Maharaja Institute of Technology \\ Coimbatore-641407, India.
}

\begin{abstract}
A multilevel inverter is mainly used to synthesize a near sinusoidal voltage from several levels of dc voltages. As number of levels increases, the synthesized output waveform has more steps, which provides a staircase wave that approaches a desired waveform. The harmonic distortion of the output wave decreases, approaching zero as the number of voltage levels increases. This paper spotlights the performance analysis of a five level inverter with coupled inductors. It reduces the total harmonic distortion in the output voltage waveform by using a single dc source. It is capable of solving capacitor voltage unbalance problem. A PI controller is used to regulate the output voltage of the inverter. The sinusoidal pulse width modulation scheme has been used to control the switches. With sinusoidal pulse width modulation, several pulses are produced per half cycle. The main objective of the work is to obtain a five level ac output voltage and to analyze the performance of the multilevel inverter. The MATLAB/ Simulink software package is used to analyze the results.
\end{abstract}

\section{Keywords}

Multilevel Inverter, Pulse Width Modulation, coupled inductors, DC voltage capacitor

\section{INTRODUCTION}

In recent years, industry has begun to demand higher power equipment, which now reaches the megawatt level. Controlled ac drives in the megawatt range are usually connected to the medium-voltage network. Today, it is hard to connect a single power semiconductor switch directly to medium voltage grids $(2.3,3.3,4.16$, or $6.9 \mathrm{kV})$. For these reasons, a new family of multilevel inverters has emerged as the solution for working with higher voltage levels.

By increasing the number of levels in the inverter, the output voltages have more steps generating a staircase waveform, which has a reduced harmonic distortion. However, a high number of levels increases the control complexity and introduces voltage imbalance problems [1]. Presented the most important topologies like diode-clamped inverter (neutral-point clamped), capacitor-clamped (flying capacitor), and cascaded multicell with separate dc sources. This paper presents the most relevant control and modulation methods developed for this family of converters: multilevel sinusoidal pulse width modulation, multilevel selective harmonic elimination, and space-vector modulation. [2] presented a bibliographical review of cascaded multi cell inverters, its working principle, circuit topologies, control techniques, and industrial applications. Cascaded multilevel inverters synthesize a medium voltage output based on a series connection of power cells which use standard lowvoltage component configurations. [3] presented a survey on Neutral-Point-Clamped Inverters. Neutral-point-clamped (NPC) inverters are the most widely used topology of multilevel inverters in high-power applications (several megawatts). This paper discusses the main fields of application and presents some technological problems such as capacitor balance and losses [3].

[4] introduced a multilevel inverter using series/parallel conversion of $\mathrm{dc}$ voltage sources. The proposed inverter can output more numbers of voltage levels in the same number of switching devices by using this conversion[4].introduced the control and design of a modular multilevel cascade BTB system using bidirectional isolated DC/DC converters. The major problems in the existing systems are availability of multiple dc voltage sources, risk of unbalanced dc capacitor voltages, and split of dc link capacitor is needed. This paper presents a single phase multilevel inverter with single dc source and coupled inductors. Coupled inductors will perform as an adder of the two input voltage and without the help of the coupled inductors, this inverter will not be able to output five-level voltage [5].

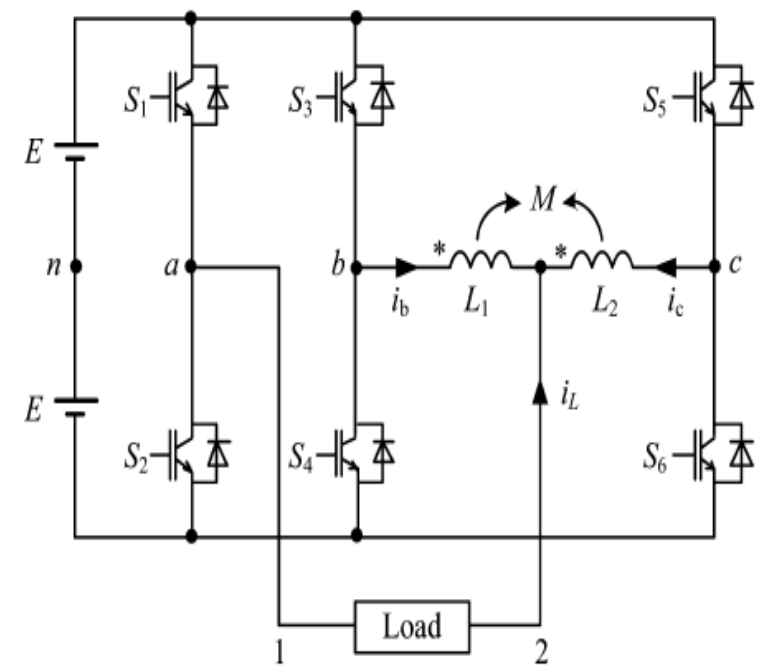

Fig 1: Single Phase Five Level Inverter

Figure. 1 shows the circuit diagram of a single phase five level inverter with coupled inductors. This inverter requires only one dc source and the split of the dc voltage capacitor is also avoided. This inverter completely eliminates the dc voltage balancing problem. This inverter can also reduce the THD of its output waveform. With the help of coupled inductors it is possible to output five-level voltage with only one dc voltage source. So the role of the coupled inductors is very important in this five level inverter. Consider the two coupled inductors with the same number of turns or obtained by a center-tapped inductor [11].

The voltage equations of the coupled inductors are given by,

$$
\begin{aligned}
& \frac{\left(M+L_{\sigma}\right) d i_{b} \int d t-M d i_{c}}{d t}=u_{b n}-u_{2 n} \\
& \frac{\left(M+L_{\sigma}\right) d i_{e} / d t-M d i_{b}}{d t}=u_{c n}-u_{2 n}
\end{aligned}
$$


According to Kirchhoff's current law,

$$
\begin{aligned}
& \bar{i}_{b}+\bar{x}_{c}+\bar{i}_{L}=0 \\
& u_{2 n}=\frac{u_{b n}+u_{c n}+L_{\sigma} d i_{L} / d t}{2}
\end{aligned}
$$

This shows that the coupled inductors will perform as an adder of the two input voltage at the non-common-connected terminals with the common-connected terminal as the output. Without the help of the coupled inductors, this inverter will not be able to produce five-level output voltage.

Table 1. Switching States and Output Voltage of the Five

\begin{tabular}{|c|c|c|c|}
\hline $\mathbf{S}_{\mathbf{1}}$ & $\mathbf{S}_{\mathbf{3}}$ & $\mathbf{S}_{\mathbf{5}}$ & $\mathbf{U}_{\mathbf{1 2}}$ \\
\hline 1 & 0 & 0 & $+2 \mathrm{E}$ \\
\hline 1 & 0 & 1 & $+\mathrm{E}$ \\
\hline 1 & 1 & 0 & $+\mathrm{E}$ \\
\hline 1 & 1 & 1 & 0 \\
\hline 0 & 0 & 0 & 0 \\
\hline 0 & 0 & 1 & $-\mathrm{E}$ \\
\hline 0 & 1 & 0 & $-\mathrm{E}$ \\
\hline 0 & 1 & 1 & $-2 \mathrm{E}$ \\
\hline
\end{tabular}

Table 1 shows the switching states and output voltage of the five level inverter.

\section{PROPOSED SYSTEM}

Figure. 2 shows the block diagram of the proposed closed loop five level inverter systems. It mainly consists of a bridge rectifier, multilevel inverter and PI controller. The unregulated ac supply is converted into unregulated dc by using a bridge rectifier. This unregulated dc voltage act as the dc source of multilevel inverter. The PI controller regulates the output voltage of the proposed system. The switches in the multilevel inverter can be controlled by using Pulse Width Modulation.

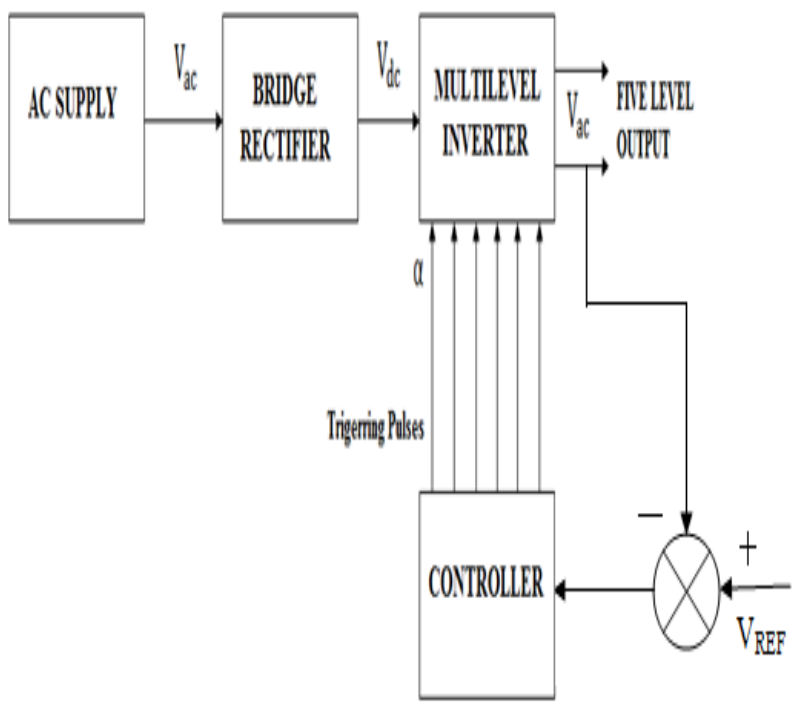

Fig 2: Block Diagram of the Proposed System

IGBT in the five level inverter is controlled by the sinusoidal pulse width modulation. In sinusoidal pulse width modulation, carrier signal is a triangular wave and reference signal is a sine wave. By comparing the reference signal with the carrier wave gating pulses are generated. The main advantage of PWM (Pulse Width Modulation) is that the power loss in the switching device is very less.

\section{SIMULATION}

The proposed closed loop system can be simulated using MATLAB/SIMULINK software. The various parameters of the inverter used for simulation is shown in Table 2.

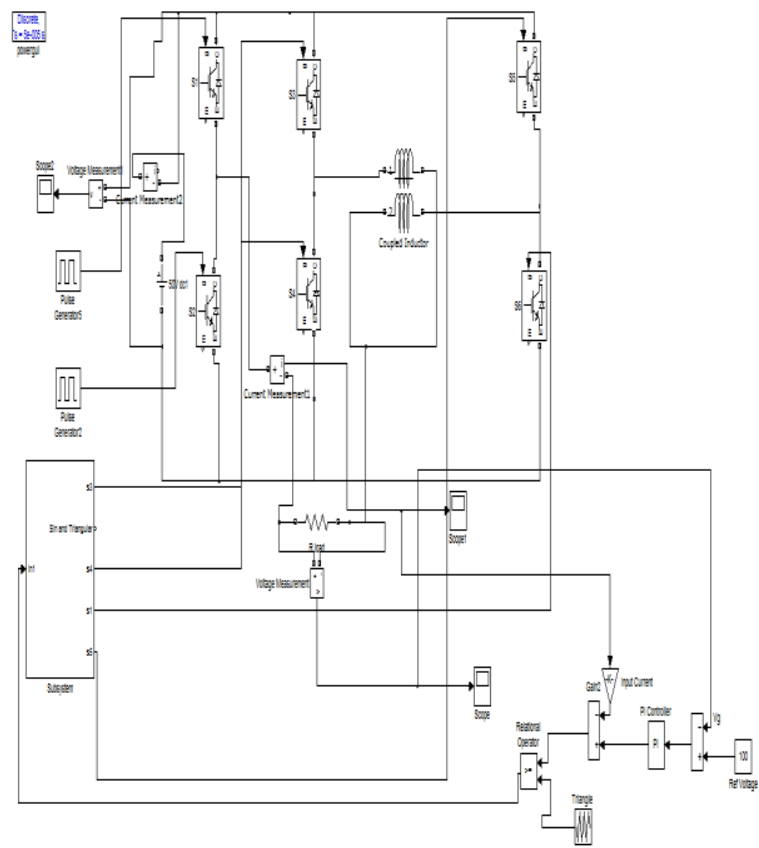

Fig 3: Closed loop simulink model 


\begin{tabular}{|l|l|l|}
\hline \multicolumn{2}{|c|}{ Table 3. Parameters of Inverter } \\
\hline SL.NO. & PARAMETERS & VALUE \\
\hline 1. & DC Link Voltage & $50 \mathrm{v}$ \\
\hline 2. & Mutual Inductance & $1 \mathrm{mH}$ \\
\hline 3. & Self-Inductance & $1 \mathrm{mH}$ \\
\hline 4. & Load Resistance & $2 \mathrm{k} \Omega$ \\
\hline
\end{tabular}

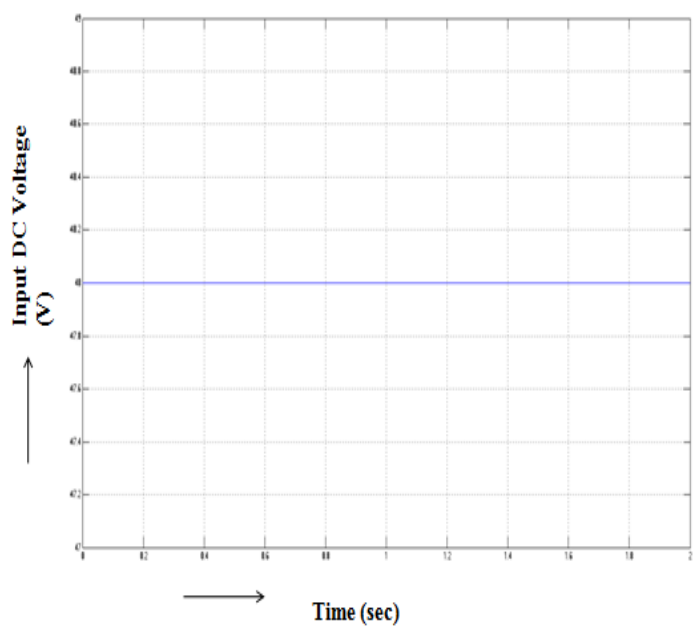

Fig 5: DC Input Voltage

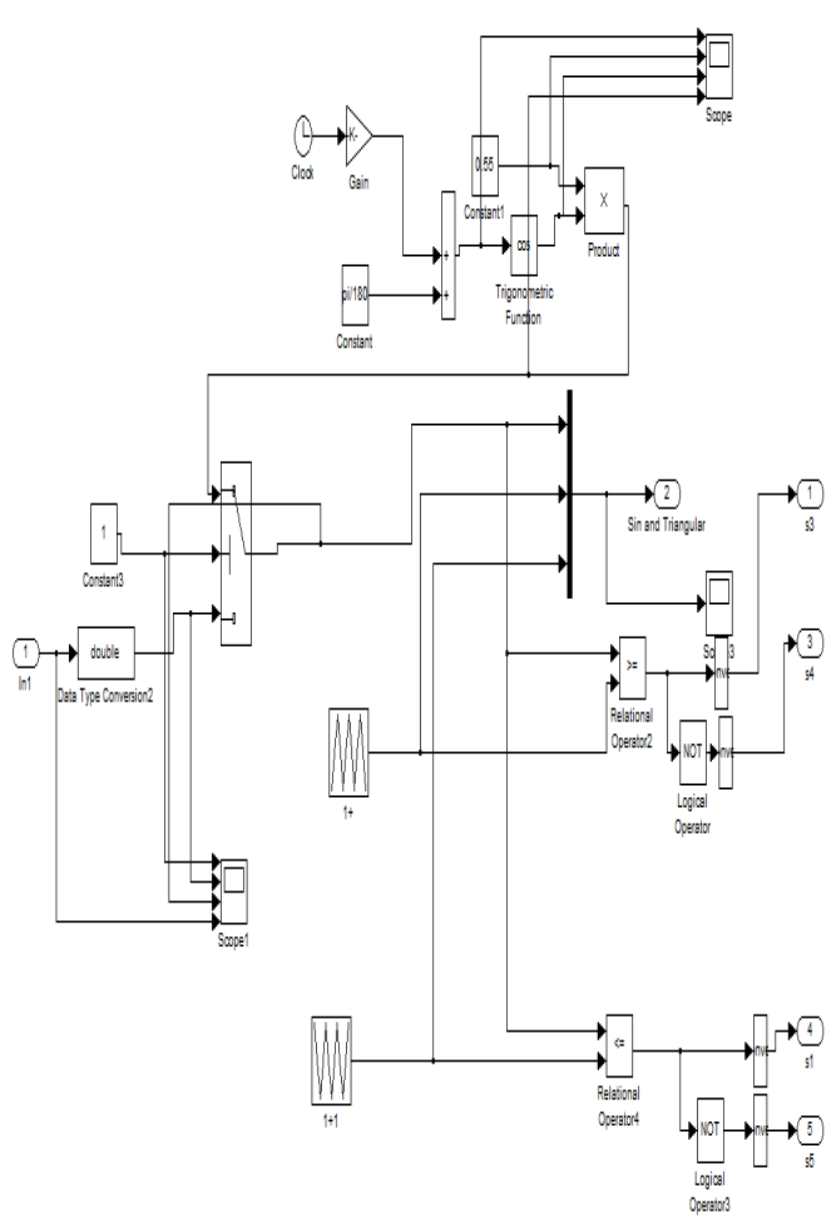

Fig 4: Simulink Model for Pulse Generation

Figure. 3 shows the simulink model of the proposed system, By IGBT using a PI controller. It consists of multilevel inverter, pulse generation circuit and PI controller. Figure. 4 shows the simulink model for pulse generation. In this system sinusoidal PWM techniques is used.

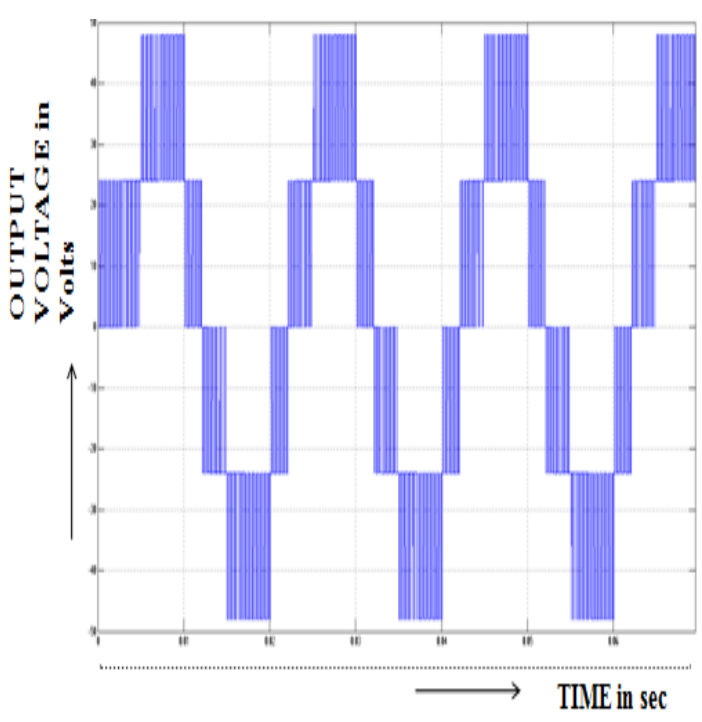

Fig 6: Five Level Output Voltage Waveform

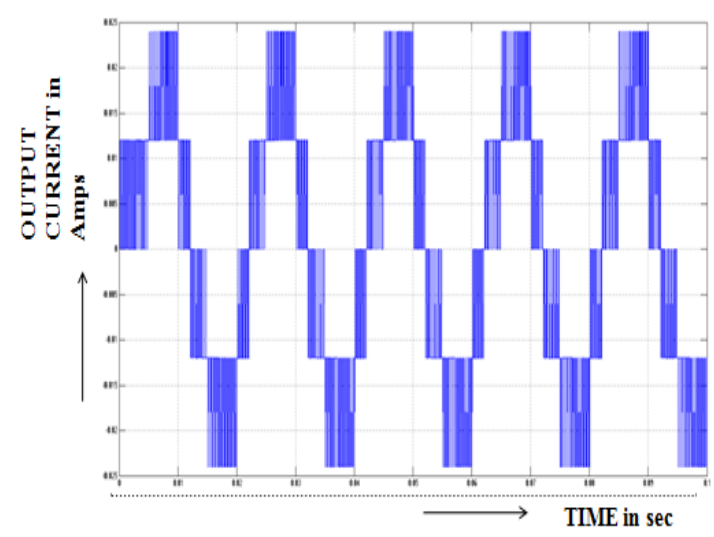

Fig 7: Output Current Waveform 

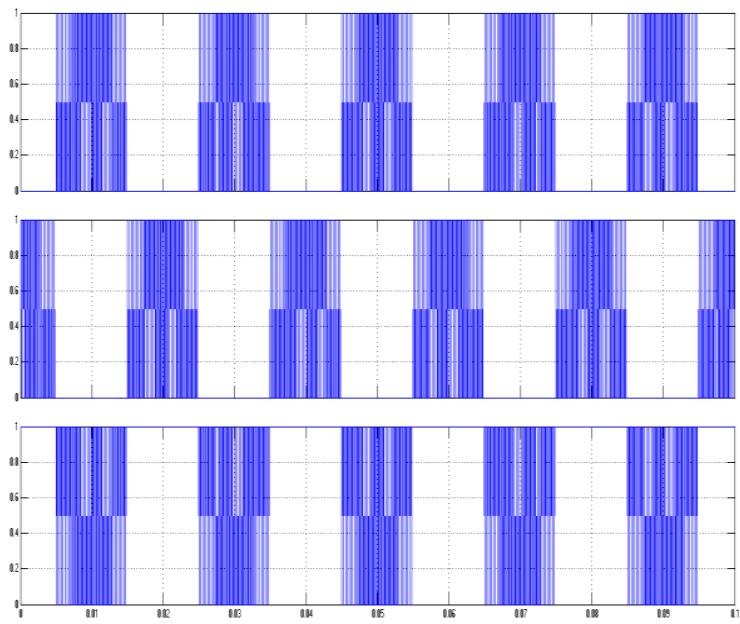

Fig 8: Triggering Pulses

Figure. 5 shows the DC input voltage given to the multilevel inverter. Figure. 6 shows the five level output voltage of the multilevel inverter. Figure. 7 shows the output current of the multilevel inverter. Figure. 8 shows the triggering pulses given to the switches.

In order to verify the validity of the topology with the Sinusoidal Pulse Width modulation scheme in this work, the proposed inverter is tested with $\mathrm{R}$ load. The parameters of this inverter are listed in Table 3. From the simulation results it can be seen that the output voltage of the inverter has five levels.

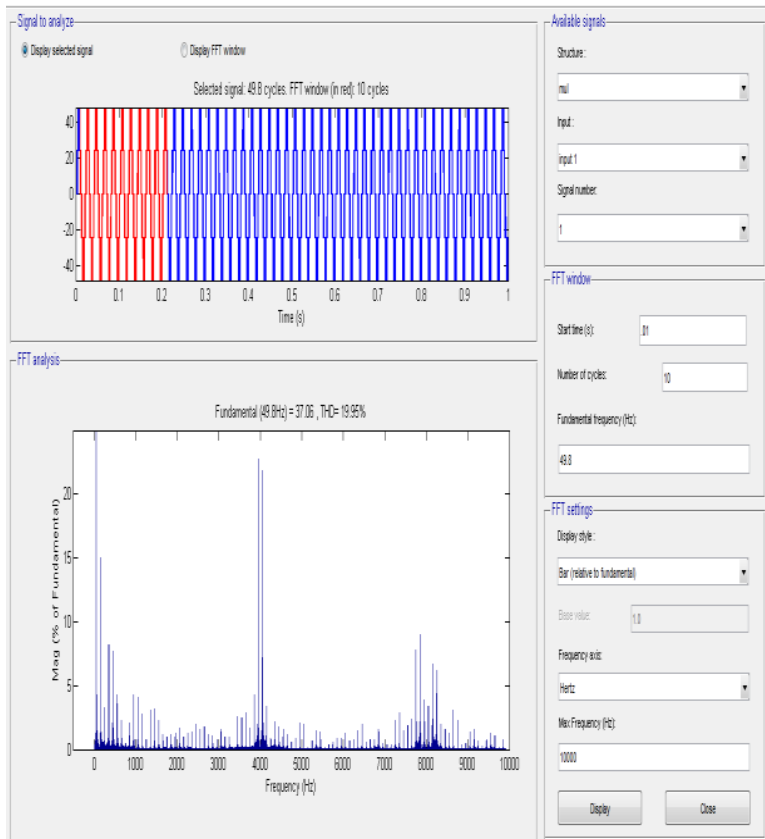

Fig 9: FFT Analysis of Output Voltage Waveform

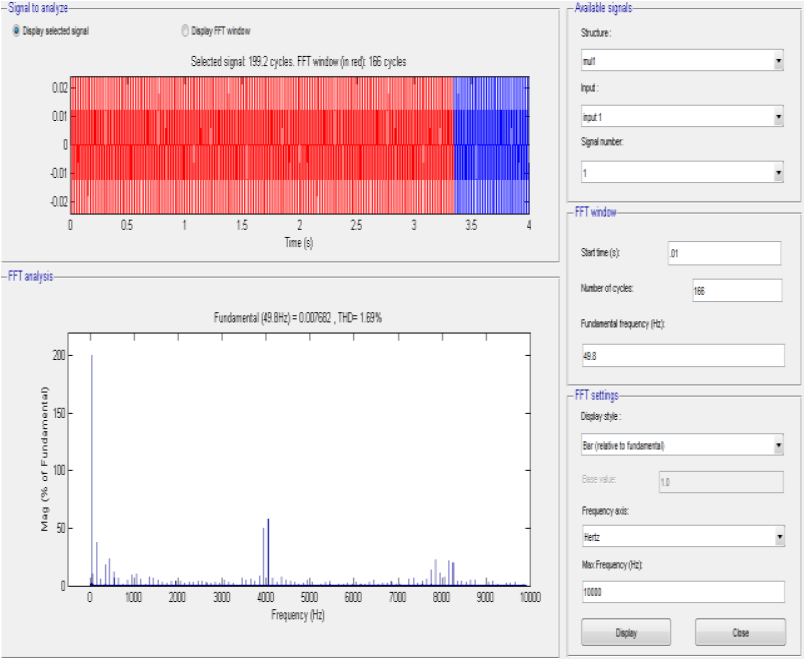

Fig 10: FFT Analysis of Output Current Waveform

The FFT analysis of output voltage waveform is shown in Figure.9 and FFT analysis of output current waveform is shown in Figure.10.

\section{CONCLUSION}

This paper introduces a novel single-phase five-level inverter based on coupled inductors. Operation mechanism of this inverter was analyzed and the sinusoidal pulse width modulation technique is used. A PI controller is used to regulate the output voltage of the inverter. The Matlab/ Simulink software is used to analyze the results. This inverter can give five-level voltage with only one dc source and no split of the dc voltage capacitor, avoiding the voltage balancing problem.

From the FFT analysis it can be seen that, the THD of output current waveform is $1.69 \%$ and that of output voltage waveform is $19.95 \%$. The proposed inverter can reduce the THD of its output waveform.

However, the switches taking the high current have lowswitching frequency while the switches taking the low current have high-switching frequency. Therefore, the presented topology is very suitable for low to medium power applications, especially for high-current cases.

\section{REFERENCES}

[1] J.Rodriguez, J.S.Lai and F.Z.Peng, "Multilevel Inverters: A Survey of topologies, controls, and applications", IEEE Trans. Ind. Electron, vol.49, no.4, pp. 724-738, Aug. 2002.

[2] M.Malinowski, K.Gopakumar, J.Rodriguez, and M.A. Perez, "A Survey on Cascaded Multilevel Inverters", IEEE Trans. Ind. Electron, vol.57, no.7, pp. 2197-2206, Jul 2010.

[3] J. Rodriguez, S. Bernet, P. K. Steimer, and I. E. Lizama, “A survey on neutral-point-clamped inverters," IEEE Trans. Ind. Electron., vol. 57, no. 7, pp. 2219-2230, Jul. 2010.

[4] Y. Hinago and H. Koizumi, "A single-phase multilevel inverter using switched series/parallel DC voltage sources," IEEE Trans. Ind. Electron., vol. 57, no. 8, pp. 2643-2650, Aug. 2010.

[5] H. Akagi and R. Kitada, "Control and design of a modular multilevel cascade BTB system using bidirectional isolated 
DC/DC converters," IEEE Trans. Power Electron., vol. 26, no. 9, pp. 2457-2464, Sep. 2011.

[6] D. Floricau, E. Floricau, and G. Gateau, "New multilevel converters with coupled inductors: Properties and control," IEEE Trans. Ind. Electron., vol. 58, no. 12, pp. 5344-5351, Jul. 2011.

[7] J. Salmon, A. Knight, and J. Ewanchuk, "Single phase multi-level PWM inverter topologies using coupled inductors," in Proc. IEEE Power Electron. Spec. Conf. (PESC), 2008, pp. 802-808.

[8] J. Zhao, Y. Han, X. He, C. Tan, J. Cheng, and R. Zhao, "Multilevel circuit topologies based on the switchedcapacitor converter and diode-clamped converter," IEEE
Trans. Power Electron., vol. 26, no. 8, pp. 2127-2136, Aug. 2011.

[9] H. Akagi and R. Kitada, "Control and design of a modular multilevel cascade BTB system using bidirectional isolated DC/DC converters," IEEE Trans. Power Electron., vol. 26, no. 9 , pp. 2457-2464, Sep. 2011

[10] Y.-S. Lai and F.-S. Shyu, "Topology for hybrid multilevel inverter," IEEE Proc. Electron. Power Appl., vol. 149, no. 6, pp. 449-458, Nov. 2002.

[11] Zixin Li, Ping Wang, Yaohua Li, and Fanqiang Gao, "A Novel Single-Phase Five-Level Inverter With Coupled Inductors", IEEE Trans. Power Electron., vol. 27, no.6, pp. 2716-2725,June . 2012 